\title{
Effect of short-acting beta blocker on the cardiac recovery after cardiopulmonary bypass
}

Jie Sun, Zhengnian Ding and Yanning Qian*

\begin{abstract}
The objective of this study was to investigate the effect of beta blocker on cardiac recovery and rhythm during cardiac surgeries. Sixty surgical rheumatic heart disease patients were received esmolol $1 \mathrm{mg} / \mathrm{kg}$ or the same volume of saline prior to removal of the aortic clamp. The incidence of cardiac automatic re-beat, ventricular fibrillation after reperfusion, the heart rate after steady re-beat, vasoactive drug use during weaning from bypass, the posterior parallel time and total bypass time were decreased by esmolol treatment. In conclusion: Esmolol has a positive effect on the cardiac recovery in cardiopulmonary bypass surgeries.
\end{abstract}

Keywords: Esmolol, cardiopulmonary bypass, Mitral valve replacement, heart rate, arrhythmia

\section{Background}

It has been well documented that early administration of beta-adrenergic antagonist during $\mathrm{CPB}$ or within 10 minutes after releasing of aortic clamp contributes to left ventricular function [1,2]. Also, cardioplegia contained esmolol, an ultra-short acting (9-minute half-life) cardioselective beta blocker [3], has cardioprotection in animal model and clinical patients [4-7]. However few studies have investigated beta-adrenergic antagonist on the details of the cardiac recovery and rhythm during $\mathrm{CPB}$. In this study, we therefore investigated the effect of esmolol on the cardiac recovery in rheumatic heart surgeries.

\section{Methods}

The study protocol followed the Declaration of Helsinki and was approved by the Ethics and Research Committee of Nanjing Medical University (Nanjing, P.R. China). The study was performed in a prospective randomized manner after all the patients signed written informed consents.

60 rheumatic heart disease patients undergoing elective single mitral valve replacements were enrolled in our study. Patients were randomly assigned to two groups by a computer program. 30 patients received esmolol (Qilu Pharmacy, China) $1 \mathrm{mg} / \mathrm{kg}$ prior to

\footnotetext{
* Correspondence: yanning_qian@yahoo.com.cn

Dept. of Anesthesiology, the first affiliated hospital with Nanjing Medical University/Jiangsu province hospital, Nanjing 210029, P.R. China
}

removal of the aortic clamp, while 28 received the same volume of saline. 2 patients were excluded because of cardiopericarditis. The cardiac recovery of patients was assessed on the basis of:(1) the heart auto re-beat ratio (the heart beat returns spontaneously without ventricular fibrillation or a temporary pacemaker); (2) the recovery time (time from reperfusion to steady heart beat); (3) the ratio of atrial fibrillation during weaning; (4) Ventricular fibrillation after primary re-beat (5) heart rate after steady re-beat; (6) heart rate 10 minutes after re-beat, and (7) temporary peri-operative pacemaking, (8) vasoactive drug use during weaning from $\mathrm{CPB}$. We also recorded the bypass associated time.

\section{Statistical analysis}

The data were analyzed with the software SPSS 11.0. The quantitative data were expressed as mean $\pm \mathrm{SD}$, and the difference was compared using one-factor analysis of variance. The qualitative data were compared with chi-square analysis. Fisher's exact test was used when the minimum expected count was less than five. $\mathrm{P}<$ 0.05 was considered to be significant.

\section{Results}

Following esmolol treatment, the heart underwent rebeat automatically in 26 patients, as compared to 10 patients in the control group $(\mathrm{P}<0.001)$. Ventricular fibrillation after primary re-beat happened in 9 cases in control but only 1 case in esmolol group ( $\mathrm{P}=0.005)$.
C Biomed Central

(c) 2011 Sun et al; licensee BioMed Central Ltd. This is an Open Access article distributed under the terms of the Creative Commons Attribution License (http://creativecommons.org/licenses/by/2.0), which permits unrestricted use, distribution, and reproduction in any medium, provided the original work is properly cited. 
The recovery durations were $4.1 \pm 1.3 \mathrm{~min}$ in the treatment group, and $4.4 \pm 1.5 \mathrm{~min}$ in controls $(\mathrm{P}=0.407)$. The heart rate after steady re-beat was $89.6 \pm 14.9 \mathrm{bpm}$ in control but $49.9 \pm 14.6$ in treatment group $(\mathrm{P}<$ $0.001)$. The heart rate after successful re-beat $10 \mathrm{~min}$ utes later was $94.8 \pm 14.3 \mathrm{bpm}$ in control but $91.5 \pm$ 10.5 in treatment group $(\mathrm{P}=0.310)$. Atrial fibrillation was found in 11 cases in control and 10 cases in esmolol group ( $P=0.786)$. Two of the control group required temporary pacemaker, compared to 3 patients in the treatment group $(\mathrm{P}=1.000)$. Eleven patients in control group needed vasoactive drug during weaning from bypass while only three in esmolol group $(P=0.014)$. (Figure 1 to Figure 2)
A

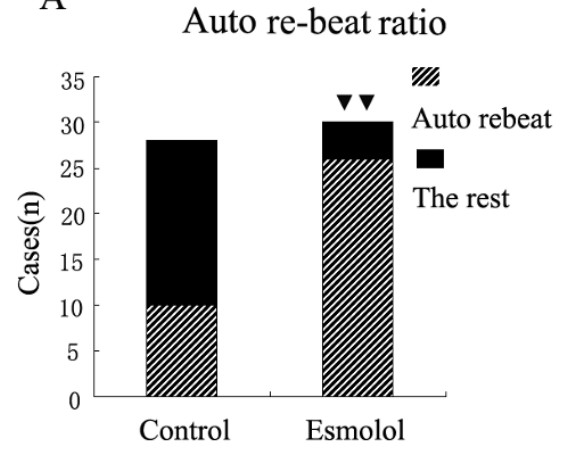

$\mathrm{C}$

Recovery duration

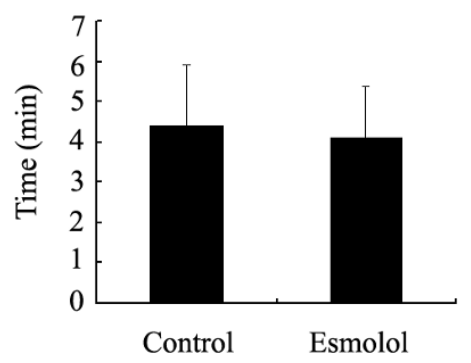

E

Temporary peri-operative pacemaking

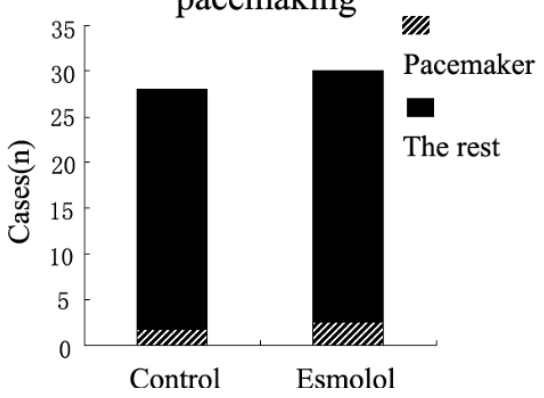

$\mathrm{B}$

VF after primary rebeat

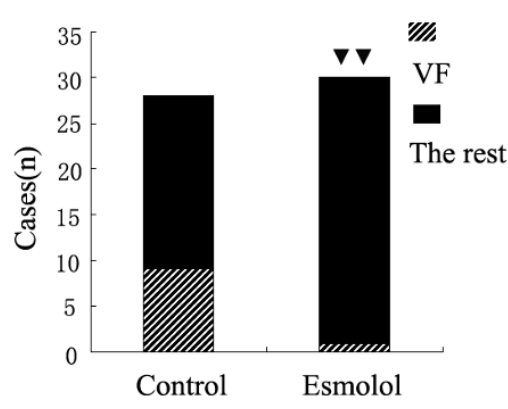

$\mathrm{D}$

AF during weaning

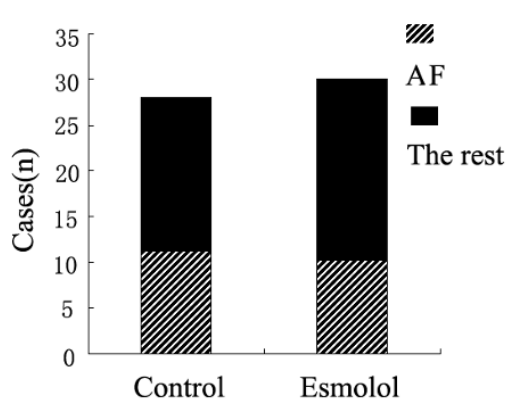

F

Vasoactive drug use

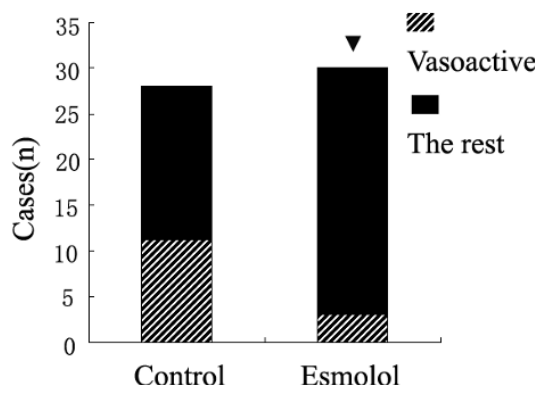

Figure 1 The heart recovery data after unclamping. A: The auto re-beat ratio in the control group and esmolol group. (two black triangles) $\mathrm{P}$ $<0.01$ compared with control group. B: Ventricular fibrillation ratio in the control group and esmolol group. (two black triangles) $\mathrm{P}<0.01$ compared with control group. VF represents for Ventricular fibrillation. C: The recovery duration (time from reperfusion to steady heart beat) in the two groups. min represents minute. D: Atrial fibrillation during weaning from CPB. AF represents atrial fibrillation. E: Temporary peri-operative pacemaking use in the two groups. F: Vasoactive drug use in the two groups. (one black triangle) $P<0.05$ compared with control group. 


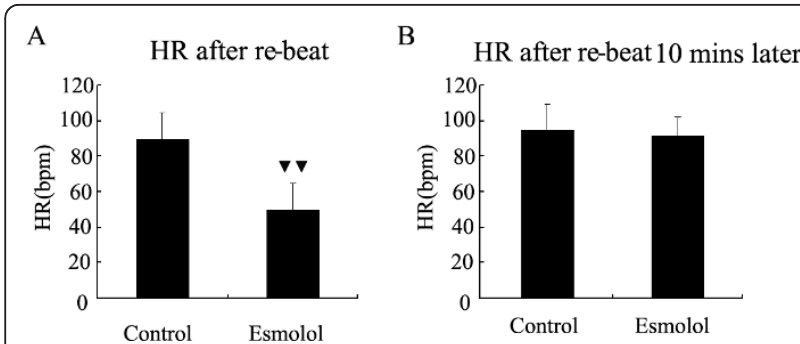

Figure 2 HR after unclamping. A: Heart rate after successful rebeat. (two black triangles) $P<0.01$ compared with control group. HR represents heart rate and bpm represents beat per minute. B: Heart rate ten minutes after successful re-beat. HR represents heart rate and bpm represents beat per minute.

The aortic-cross clamping time was $39.9 \pm 9.1 \mathrm{~min}$ utes in control group and $39.4 \pm 8.0$ minutes in esmolol group $(\mathrm{P}=0.827)$. The posterior parallel time (time from unclamping to weaning) was $29.6 \pm 8.9$ minutes in control group and $24.3 \pm 7.8$ minutes in esmolol group $(\mathrm{P}=0.007)$. The bypass time was $69.9 \pm 9.0$ minutes in control group and $63.7 \pm 10.9$ minutes in esmolol group $(\mathrm{P}=0.022)$. (Figure 3$)$

\section{Discussion}

Our study found a positive effect of beta blocker on the prevention of ventricular arrhythmia in surgical heart disease patients. In addition, we also identified that esmolol increased the auto re-beat success rate, decreased the incidence of ventricular fibrillation after primary re-beat, and maintained better myocardial oxygen delivery and consumption balance without prolonging bypass time. On the contrary, esmolol treatment

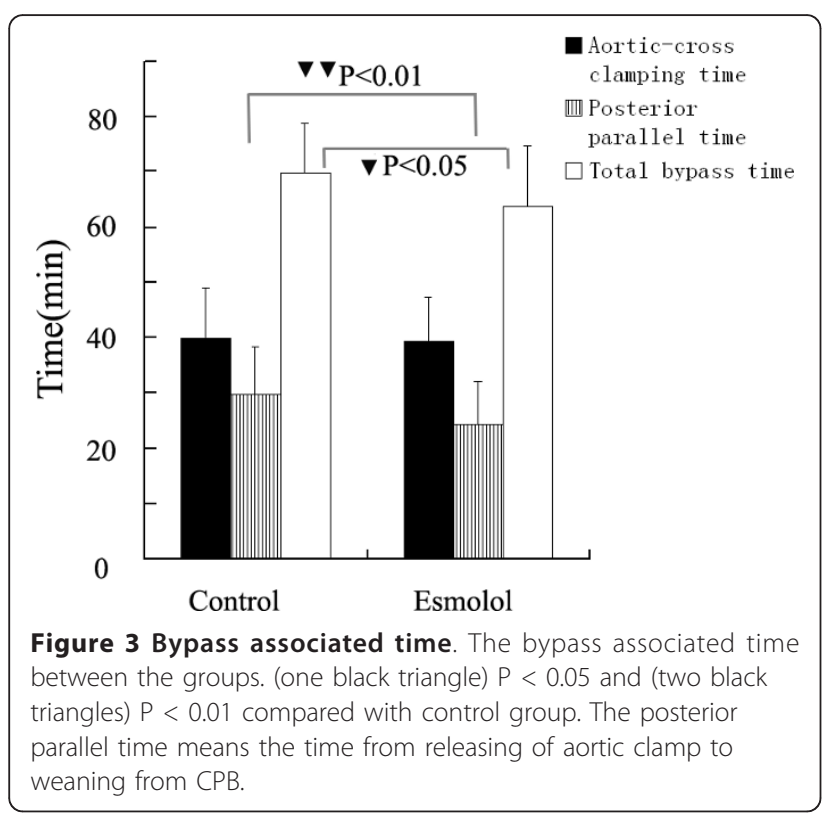

prior to removal of the aortic clamp decreased the posterior bypass time.

Esmolol treatment did not increase the need for temporary cardiac pacemaker in order to maintain the target heart rate after bypass. Because it is a very short acting beta blocker, and it seldom depresses the heart rate or contractility when administered in the early stage. In addition, esmolol improved the cardiac recovery and the heart oxygen delivery and consumption balance, which increased the myocardial energy stores and thereby benefit for the weaning process.

More and more physicians incline to use beta blocker to treat various arrhythmias including ventricular arrhythmia in non-surgical patients [8-11]. And in accordance with those studies, we also found that beta blocker had positive effect on the recovery and ventricular arrhythmias in cardiac surgery patients, which indicated beta blocker was another alternate to benefit the heart rhythm in $\mathrm{CPB}$ patents. Although there are some studies and meta-analysis about esmolol in cardiac surgery [12-16], most of them are about CABG patients and about peri-operative complications. Ours is more detailed on the cardiac recovery and heart rhythm during CPB intra-operatively, which is almost scarce in the present clinical researches.

In conclusion, esmolol has a positive effect on the cardiac recovery in $\mathrm{CPB}$ surgeries.

List of abbreviations

CPB: cardiopulmonary bypass; CABG: coronary artery bridge grafting.

\section{Acknowledgements}

We thank Dr. Liang Yongnian for his assistance in cardiopulmonary bypass work.

\section{Authors' contributions}

First author: SJ participated in the sequence alignment and drafted the manuscript.

Second author: DZ participated in the design of the study and performed the statistical analysis.

Correspondence author: QY conceived of the study, and participated in its design and coordination.

All authors have read and approved the final manuscript.

\section{Competing interests}

The authors declare that they have no competing interests.

Received: 8 July 2011 Accepted: 19 August 2011

Published: 19 August 2011

\section{References}

1. Booth JV, Spahn DR, McRae RL, Chesnut LC, El-Moalem H, Atwell DM, Leone BJ, Schwinn DA: Esmolol improves left ventricular function via enhanced beta-adrenergic receptor signaling in a canine model of coronary revascularization. Anesthesilogy 2002, 97:162-169.

2. Cork RC, Azari DM, McQueen KA, Aufderheide S, Mitchell M, Naraghi M: Effect of esmolol given during cardiopulmonary bypass on fractional area of contraction from transesophageal echocardiography. Anesth Analg 1995, 81:219-224.

3. Sum CY, Yacobi A, Kartzinel R, Stampfli H, Davis CS, Lai CM: Kinetics of esmolol, an ultra-short-acting $\beta$-blocker, and of its major metabolite. Clin Pharmacol Ther 1983, 34:427-434. 
4. Bessho R, Chambers DJ: Myocardial protection with oxygenated esmolol cardioplegia during prolonged normothermic ischemia in the rat. $J$ Thorac Cardiovasc Surg 2002, 124:340-351.

5. Scorsin M, Mebazaa A, Al Attar N, Medini B, Callebert J, Raffoul R, Ramadan R, Maillet JM, Ruffenach A, Simoneau F, Nataf P, Payen D, Lessana A: Efficacy of esmolol as a myocardial protective agent during continuous retrograde blood cardioplegia. J Thorac Cardiovasc Surg 2003, 125:1022-1029.

6. Fallouh HB, Bardswell SC, McLatchie LM, Shattock MJ, Chambers DJ, Kentish JC: Esmolol cardioplegia: the cellular mechanism of diastolic arrest. Cardiovasc Res 2010, 87:552-560.

7. Fannelop T, Dahle GO, Matre K, Moen CA, Mongstad A, Eliassen F, Segadal L, Grong K: Esmolol before 80 min of cardiac arrest with oxygenated cold blood cardioplegia alleviates systolic dysfunction. An experimental study in pigs. Eur J Cardiothorac Surg 2008, 33:9-17.

8. Bassiakou E, Xanthos T, Papadimitriou L: The potential beneficial effects of beta adrenergic blockade in the treatment of ventricular fibrillation. Eur J Pharmacol 2009, 616:1-6.

9. Jingjun L, Yan Z, Dongdong Z, Guosheng L, Mingwei B: Effect and mechanism of esmolol given during cardiopulmonary resuscitation in a porcine ventricular fibrillation model. Resuscitation 2009, 80:1052-1059.

10. Deng CY, Lin SG, Zhang WC, Kuang SJ, Qian WM, Wu SL, Shan ZX, Yang M, Yu XY: Esmolol inhibits $\mathrm{Na}+$ current in rat ventricular myocytes. Methods Find Exp Clin Pharmacol 2006, 28:697-702.

11. Killingsworth CR, Wei CC, Dell'Italia L, Ardell UL, Kingsley MA, Smith WM, Ideker RE, Walcott GP: Short-acting beta-adrenergic antagonist esmolol given at reperfusion improves survival after prolonged ventricular fibrillation. Circulation 2004, 109:2469-2674.

12. Zangrillo A, Turi S, Crescenzi G, Oriani A, Distaso F, Monaco F, Bignami E, Landoni G: Esmolol reduces perioperative ischemia in cardiac surgery: a meta-analysis of randomized controlled studies. I Cardiothorac Vasc Anesth 2009, 23:625-632.

13. Chauhan S, Saxena N, Rao BH, Singh RS, Bhan A: A comparison of esmolol and diltiazem for heart rate control during coronary revascularisation on beating heart. Ann Card Anaesth 2000, 3:28-31.

14. Arar C, Colak A, Alagol A, Uzer SS, Ege T, Turan N, Duran E, Pamukcu Z: The use of esmolol and magnesium to prevent haemodynamic responses to extubation after coronary artery grafting. Eur I Anaesthesiol 2007, 24:826-831.

15. Boldt J, Brosch C, Lehmann A, Suttner S, Isgro F: The prophylactic use of the beta-blocker esmolol in combination with phosphodiesterase III inhibitor enoximone in elderly cardiac surgery patients. Anesth Analg 2004, 99:1009-1017.

16. Nlodromitis EK, Tasouli A, Andreadou I, Bofilis E, Zoga A, Cokkinos P, Kremastinos DT: Intravenous atenolol and esmolol maintain the protective effect of ischemic preconditioning in vivo. Eur J Pharmacol 2004, 499:163-169.

doi:10.1186/1749-8090-6-99

Cite this article as: Sun et al.: Effect of short-acting beta blocker on the cardiac recovery after cardiopulmonary bypass. Journal of Cardiothoracic Surgery 2011 6:99.

\section{Submit your next manuscript to BioMed Central and take full advantage of:}

- Convenient online submission

- Thorough peer review

- No space constraints or color figure charges

- Immediate publication on acceptance

- Inclusion in PubMed, CAS, Scopus and Google Scholar

- Research which is freely available for redistribution

Submit your manuscript at www.biomedcentral.com/submit
Ciomed Central 